132 | InterAção

\title{
CONSTRUTIVISMO E TEORIA CRÍTICA: UMA POSSIBILIDADE DE DIÁLOGO ENTRE BOURDIEU E COX NAS RELAÇÕES INTERNACIONAIS
}

Bruno Haeming ${ }^{1}$

\section{Resumo}

No presente artigo é feita a comparação entre a abordagem construtivista, utilizando as ideias de Pierre Bourdieu, com a Teoria Crítica representada pelas ideias de Robert Cox. Parte-se da hipótese de que é possível comparar tais autores e ideias, em função de partilharem ontologias semelhantes, reflexivas e críticas ao positivismo científico, em que a visão estrutural da sociedade se faz presente em categorias socialmente e historicamente construídas. Ao final se concluiu que as comparações entre os autores são possíveis, desde que sejam respeitadas as particularidades da construção das ideias de ambos, partindo do campo comum entre os autores, que seja, as estruturas sociais e reflexividade.

Palavras-chave: Construtivismo. Teoria Crítica. Pierre Bourdieu. Robert Cox. Reflexividade. Ontologia Reflexiva.

\begin{abstract}
This article aimed to compare the constructivist approaches in IR through Pierre Bourdieu's ideas with Critical Theory represented by Robert Cox ideas. Our main hypothesis is that it is possible to compare these authors ideas, due to their shared reflexive ontology critical to scientific positivism, in which structural view of society is present in categories socially and historically constructed, giving dynamism and criticism in the way that science is made. At the end it we concluded that comparisons between the authors are possible, and the hypothesis is confirmed as well, since the peculiarities of the construction of both ideas are respected, not incurring methodological errors or bias in the research.
\end{abstract}

Keywords: Constructivism. Critical Theory. Pierre Bourdieu. Robert Cox. Reflexivity. Reflexive Ontology.

\footnotetext{
1 Doutorando em Relações Internacionais, com ênfase em Política Internacional, pela Pontifícia Universidade Católica de Minas Gerais (PUC Minas). Bachareal em Ciências Econômicas pela Universidade Federal de Santa Catarina (2015), Mestre em Relações Internacionais, com ênfase em Economia Política Internacional, pela Universidade Federal de Santa Catariana (2018). Bolsista da Coordenação de Aperfeiçoamento de Pessoal de Nível Superior (CAPES).
} 
133 | InterAção

\section{INTRODUÇÃO}

As teorias das Relações Internacionais sofreram impactos ao longo do tempo, provocando mudanças na forma de se fazer e pensar ciência. O primeiro movimento de "transformação" foi o behaviorismo, que buscou aplicar uma metodologia diferente das que vigiam nos estudos internacionais com base no positivismo científico ${ }^{2}$ utilizando os escritos seminais de Popper (1934) dentro da filosofia da ciência. Em Popper (1934) existe uma narrativa que expõe uma abordagem normativa de ciência, baseada na racionalidade, utilizando a dedução como forma de teorizar e construir hipóteses, e a construção de teorias demarcadas pelo critério da falseabilidade.

Tal lógica de pesquisa científica ganhou adeptos em diversas áreas do conhecimento, nas ciências sociais com bastante força, e dentro das Relações Internacionais se colocou em perspectiva o pensamento científico associado ao positivismo de um lado, e de outro o tradicionalismo, que na visão de alguns, era carente de critérios científicos e carregado de incoerências (KAPLAN,1966).

Waltz (1979) é outro texto autor que dialoga com o movimento behaviorista, e teve grande impacto para as Relações Internacionais (RI). Esses trabalhos foram marcos para as Relações Internacionais e expressam um período da construção do conhecimento dentro da disciplinam que dialogou com behaviorismo.

Por outro lado, a Teoria Crítica e o Construtivismo tem por essência a expressão de um movimento de antagonismo ao consenso posto nas ciências sociais e nas RI, e propõem agendas e temas de pesquisa novos.

2 Como positivismo é entendido a forma de fazer ciência advinda dos positivistas lógicos, e revisitada por Karl Popper no ser Logik der Forschung, 1934. 


\section{$134 \mid$ InterAção}

A Teoria Crítica nasce de uma crítica estruturada à ortodoxia científica, e a partir da obra de Cox (1981), problematizou-se a função da ciência, situando-a como uma busca do conhecimento influenciada pelas forças sociais, com interesses moldados de forma dialética entre estrutura e agente, produzindo uma forma de pensar e agir, nem sempre guiada pela busca da "verdade" de forma neutra, mas escondendo interesses políticos e econômicos. Nessa obra Cox (1981) coloca a importância da teoria em seu caráter intersubjetivo de construção e de ferramenta para a ação: ela é feita num contexto, por alguém, e para alguém.

Há também outro movimento intelectual contestatório nas RI: o Construtivismo. Ele trouxe a relação agente-estrutura em enfrentamento à visão monolítica, racionalista e central do Estado na política entre as nações - vide a supracitada obra de (WALTZ,1979) - que vigorava nas Relações Internacionais, mostrando que além do Estado, existiam instituições diversas e indivíduos, e que esses possuem agência: a interação entre agente e estrutura produz política, não apenas se deve analisar um ou outro de maneira isolada (WENDT, 1987).

Wendt (1992) mostra que identidade e interesse são importantes para analisar a ação dos Estados e suas políticas, e a socialização dos indivíduos tem peso para se compreender as razões envolvidas numa decisão ou em uma política. Logo, a visão que um indivíduo tem de si mesmo ou de outro país deve ser levada em conta. Nessa perspectiva o Estado sai de uma abstração complexa e inviolável, e se torna passível de análise pormenorizada, abrindo espaço para novas variáveis e problematizações. Logo, situa-se o construtivismo como uma narrativa que lança luz para uma mudança na compreensão do jogo de poder nos Estados e entre os Estados.

Mesmo que tais mudanças sejam difíceis, a socialização tem peso e seus efeitos são sentidos, abrindo assim as perspectivas de ação e, no limite, os arranjos de poder vigentes, (HOPF, 1998). 


\section{5 | InterAção}

O elo entre as teorias que se pretende mostrar é baseado nos escritos de Guzzini (2000), que aborda o construtivismo sob uma perspectiva social (construtivismo social nas palavras do autor), traz para dentro do debate epistemológico e científico as ideias de Pierre Bourdieu e sua análise estrutural da sociedade, em especial as categorias de Campo, Habitus e capital.

A abordagem construtivista ganha forma com as categorias de Pierre Bourdieu, e se torna uma agenda de pesquisa comparável, compatível (respeitando as construções taxonômicas e teóricas dos autores) e complementar às ideias de Robert Cox. É preciso pontuar que o construtivismo a partir da abordagem feita por Guzzini (2000) não é consensual, e ${ }^{3}$ existem muitas convergências entre as vertentes do construtivismo, mas também há divergências mais amplas que no presente trabalho não serão especificadas (HOPF, 1998).

A hipótese central desse artigo é que: há convergências e complementaridades entre as ideias de Pierre Bourdieu, sob a luz do que buscava o construtivismo nas Relações Internacionais em seu caráter teórico social e reflexivo, e a Teoria Crítica sob a perspectiva de Robert Cox (COX, 1981). Das convergências possíveis, uma delas diz respeito ao uso de categorias que levam em conta a construção histórica da sociedade, e que por ambas as abordagens compartilharem de semelhante ontologia, explicam uma sociedade de relações intersubjetivas numa dinâmica historicamente construída.

Para tal empreendimento, colocar-se-á o construtivismo das Relações Internacionais e sua conexão com os escritos de Pierre Bourdieu, principalmente em Bourdieu (1989), mais precisamente utilizando as categorias de Campo, Habitus e capital. Cox (1981) será usado para, de forma comparativa, mostrar que ambos compartilham de uma visão ontológica semelhante. Mas também serão

\footnotetext{
${ }^{3}$ Não há a adoção da divisão feita por Hopf (1998) o que se quer é chamar a atenção para a existência de diferenças dentro da própria abordagem construtivista.
} 
136 | InterAção

pontuadas divergências entre os autores, suas categorias e finalidades, para que seja possível construir pontes de dialogo no limite da possibilidade e limitação teórica de cada um.

A primeira seção versará sobre o construtivismo nas Relações Internacionais e a presença de Pierre Bourdieu na disciplina, entrando em consonância com o objetivo deste trabalho, conectando à seção dois, onde estará a descrição das ideias de Robert Cox. A terceira parte relacionará Bourdieu e suas categorias analíticas de Campo, Habitus e Capital, com a Estrutura Histórica de Cox e seus elementos fundamentais. Por fim estará a conclusão e o saldo da comparação aqui proposta.

\section{A VISÃO CONSTRUTIVISTA EM CONTATO COM PIERRE BOURDIEU}

\subsection{CONSTRUTIVISMO}

O construtivismo se consolidou como uma saída teórica para os questionamentos às teorias estruturais, ou sistêmicas, representadas pelo neorealismo nas Relações Internacionais ${ }^{4}$.

Lapid (1989) fala que o construtivismo se inclui em um “Terceiro Debate” dentro do campo das RI, que seria uma resposta ao positivismo, utilizando um debate gestado dentro da Filosofia da Ciência entre o positivismo de Karl Popper, e se opondo a essa perspectiva, uma outra perspectiva de Kuhn (2000) com uma visão paradigmática da ciência, somando-se com as ideias de Lakatos (1970) e seus Programas de Pesquisa Científica ( PPC). O efeito disso nas RI foi uma série

${ }^{4}$ Doravante também nomeada como RI. 


\section{7 | InterAção}

de escritos que contestavam, além da ciência positivista, os axiomas e categorias que regiam a pesquisa no campo como um todo.

Dentro da perspectiva lançada por Kuhn (2000) podemos buscar uma análise para as RI. No caso a Ciência Normal, ou a forma de fazer ciência e teoria que vigia como central para as RI, passava por questionamentos dentro do campo, e a abordagem Construtivista seria uma resposta à crise da Ciência Normal. Por uma visão "Lakatosiana", o construtivismo se insere como uma transformação no Programa de Pesquisa Científica das teorias mais populares, até porque como lembra Hopf (1998), o construtivismo não é uma teoria, e se propõe a ter uma agenda de pesquisa para resolução de problemas e elaboração de problemas de pesquisa para teorias Neoliberais Institucionais e a Neorealistas.

A partir de um esforço intelectual até então pioneiro, Wendt (1987) situa um debate nas RI que busca tirar o foco de uma ontologia estrutural do Estado, trazendo o papel da agência como relevante. Anteriormente, Waltz (1979) defendeu que o agente é apenas um mero transmissor dos estímulos que os Estados, ou a unidade de análise, sofrem do meio anárquico, que é o princípio ordenador do sistema do qual faz parte: em outras palavras o agente não tem relevância ou independência.

Como um elemento importante, e que exemplificaria o que seria o construtivismo, está em nossa visão na interpretação do mundo levando em conta o fator social. Tal coisa significa que o "Sistema Internacional" e suas categorias poderiam ser entendidos como uma construção social, (GUZZINI, 2000), e dessa forma tais categorias utilizadas para entender a política internacional teriam um significado diferente, como por outros motivos ${ }^{5}$,

\footnotetext{
${ }^{5}$ É importante ressaltar que, como mais a frente se propõe, Pierre Bourdieu não concordaria com a frase de Alexander Wendt, já que não a anarquia não seria feita pelos Estados, mas eles se situariam de forma diferente dentro dela, mesmo possuindo algum poder de agência, o sistema a priori seria hierárquico ADLER-NISSEN (2013).
} 


\section{InterAção}

defende Wendt (1992), em um título que é célebre por mostrar nele exatamente a proposta dos críticos ao positivismo: “ A anarquia é o que os Estados fazem dela” 6 .

Wendt (1992) coloca as categorias analíticas usadas pelos neorealistas sob uma perspectiva intersubjetiva, em que a balança de poder (ou balança de ameaça), auto-interesse e anarquia, teriam de ser vistas como um resultado da construção social de cada Estado, e não apenas os Estados como receptores de estimulo do princípio ordenador, gerando um resultado a partir da lógica racional da teoria.

Tal epistemologia significa que para o construtivismo o mundo é de relações intersubjetivas, e não apenas um dado que se observa na teoria partir da cognição racional-dedutiva7.Tem-se que as relações intersubjetivas também surtem efeito na forma como se enxerga a realidade, alterando percepções a depender do tempo histórico, lugar e interesse. A observação dos fatos tampouco é completamente livre de intersubjetividade entre quem analisa um fato, e a partir dele, constrói uma explicação. É com essa crítica que o construtivismo situa sua atuação científica;

Em suma, o construtivismo adverte, contra o empirismo, que a observação não é um registro passivo ou uma percepção subjetiva pura, mas que os objetos do conhecimento são construídos. Contra o idealismo epistemológico, o construtivismo argumenta que os princípios da construção do conhecimento não estão exclusivamente relacionados ao mundo dos discursos, mas constituem-se socialmente através de práticas. (BOURDIEU, 1980, p.87 apud GUZZINI, 2000, p. 160) ${ }^{8}$.

\footnotetext{
6 "Anarchy is what states make of it".

7. Atualmente há estudos como o de Kahneman (2012) que contestam a racionalidade dedutiva, mostrando um caráter adaptativo à ela, para Bigo (2011) Bourdieu já teria chegado a conclusão semelhante.

8 "To sum up, constructivism recalls against empiricism that observation is no passive recording or purely subjective perception, but that objects of knowledge are constructed. It would oppose epistemological idealism on the grounds
} 


\section{9 | InterAção}

Guzzini (2000) em seguida problematiza a questão da "dupla hermenêutica", utilizando as ideias da Teoria da Estruturação de Anthony Giddens, (GIDDENS, 1984) ${ }^{9}$, fonte da qual tanto Guzzini (2000) quanto o próprio e Wendt (1987) compartilham.

Dessa forma, tratar a ciência pela adoção de uma perspectiva de dupla hermenêutica é problematizar a interpretação do objeto de pesquisa e do próprio observador (pesquisador) do objeto, tirando do objeto a naturalização que a ciência positivista lhe dá (GUZZINI, 2000). Tanto o observador quanto o objeto fazem parte de um contexto social, e problematizá-lo no nível de quem observa e do que é observado se torna importante a partir da perspectiva construtivista.

A ação e observação tem papel central para a teoria social, particularmente uma ação intersubjetiva, e um conhecimento socialmente construído: a imagem do observador de si mesmo em relação ao objeto, assim como a compreensão que o fato faz parte do contexto social de análise são variáveis centrais dessa abordagem $^{10}$.

Guzzini (2000) ao problematizar o campo das RI, e especificamente falar do construtivismo, lança-se mão do caráter reflexivo que o construtivismo se propõe a tratar na análise da sociedade, e vai a Pierre Bourdieu em busca de conceitos para tratar tanto a epistemologia da ação e observação, como para relacionar esses dois níveis, o que seriam uma oposição a um individualismo, evitando o idealismo em que tudo é relativizado: é possível elencar

\footnotetext{
that the principles of knowledge construction are not entirely internal to discourse, but socially constituted through practices".

${ }^{9}$ Tal fonte é compartilhada tanto por Guzzini (2000) quanto pelo próprio Wendt (1987).

${ }^{10}$ Entende-se que a tentativa de estabelecer para o construtivismo uma agenda de pesquisa que parta de uma crítica à ciência, com uma abordagem epistemológica construtivista que leva em conta uma sociedade reflexiva, ou seja, que leva em conta a construção social do conhecimento (observação) e a construção social da realidade (ação).
} 
140 | InterAção

regularidades e fatos concretos para analisar a relação intersubjetiva num campo, seja pelo agente, seja pela estrutura;

[...] Isso significa que a pesquisa deve não apenas abordar o nexo entre os estímulos materiais e ideacionais e o comportamento individual, mas deve primeiramente compreender a agência de uma forma mais profunda, entendendo a evolução histórica dos esquemas de pensamento, percepção e ação, e a distribuição de capital, incluindo o capital social, em campos cuidadosamente definidos onde os agentes se encontram. (GUZZINI 2000, p.23) ${ }^{11}$

Os conceitos de Pierre Bourdier, e principalmente suas categorias de habitus, campo e capital ajudam, como supracitados, a interpretar essa relação entre estrutura e agente. Tendo isso em mente, é necessário abordar Pierre Bourdieu, e traçar as linhas que o colocam dentro do interesse das RI, em especial naqueles em que dialogam com as ideias de Robert Cox.

\subsection{PIERRE BOURDIEU NAS RELAÇÕES INTERNACIONAIS}

As ideias de Pierre Bourdieu são conhecidas através de diversos autores, RI ADLER-NISSEN (2013); LEANDER (2000); LEANDER (2011); BIGO(2011).

Tais obras buscam revisitar conceitos e temas de RI sob a luz de Pierre Bourdieu, mesmo que por vezes divergindo com o pensamento estrutural de Bourdieu - que via sua teoria como uma sociologia reflexiva e Estrutural - e

\footnotetext{
11 "Once one accepts the existence of intersubjective units of analysis, their study must become a research agenda on its own. It means that research not only addresses the nexus between material and ideal inputs and individual behaviour, but must first understand this agency in a more embedded way, understanding the historically evolving schemes of thought, perception and action, as well as the distribution of capital, including the social, in carefully defined fields where agents meet."
} 
141 InterAção

podem ser interpretadas como um " Estruturalismo Construtivista"12 (LEANDER, 2011).

A diferença também se dá entre o construtivismo dentro da RI. AdlerNissen (2013) constrói sua problemática de pesquisa e análise teórica e social no campo das RI em cima dos conceitos de identidade e normas, mas deixa de lado a variável poder, que é bastante relevante para uma análise social dentro da perspectiva de Bourdieu (BIGO, 2011).

Todavia o essencial do que se propõe Pierre Bourdieu é compartilhado por todos: analisar a sociedade e as interações intersubjetivas construídas nas dinâmicas sociais, em que os agentes agem sub suas interpretações e conhecimentos socialmente construídos (ADLER-NISSEN, 2013).

As relações intersubjetivas existem numa estrutura estabelecida. Essa é produto da interação social, e partir da análise temporal- histórica dessa estrutura, é possível compreender os fenômenos sociais, bem como as relações de poder. O ponto que importa para se analisar tais relações intersubjetivas reside na concepção de reflexividade, que é o cerne da epistemologia de Pierre Bourdieu assim como é caro para o construtivismo dentro das RI.

Em suma, a reflexividade é o ato de teorizar olhando para si, o objeto estudado como uma estrutura social, e o observador participante desse objeto enquanto sujeito que percebe, atribui, tem percepções e é também o produto dessa estrutura.

O corolário da reflexividade é perceber que o acadêmico não está livre da sua realidade social, também que a sua teoria não é isenta em atribuição de valores.

12 Ela menciona ser " Structuralist constructivism" a forma como o próprio Bourdieu caracteriza sua produção teórica, p.1. 


\section{2 | InterAção}

Neufeld (1993) e Guzzini (2000) dialogam com tal perspectiva resgatando alguns pontos do debate, colocando a reflexividade como um rompimento com o positivismo, mas em especial tratando a reflexividade criticamente, mostrando que o debate nas RI muitas vezes não cumpriu a premissa de ser crítico, e que é preciso ter isso em conta para estruturar uma linha metodológica e epistemológica que supra essa lacuna no debate: por Bourdieu ser um autor reflexivo-crítico e poderia travar uma dialogo com tal demanda do campo.

Guzzini (2000) apontas armadilhas do processo crítico, como e entrar em contradição, ou usar uma falsa reflexividade, voltando outra vez para o positivismo. Ao não se preocupar de fato com uma epistemologia reflexiva, considerando o papel da teoria e do pesquisador ao formular hipóteses e analisar dados, apenas incluindo hipóteses auxiliares às teorias já existentes, algo que ao fim apenas repete as metanarrativas positivistas e seus pressupostos basilares.

Outra armadilha é se situar num relativismo completo, que não leva em conta regularidades que conformam uma estrutura social que é produto da história (GUZZINI, 2000). Os conceitos de Campo e habitus podem auxiliar a fundamentar a percepção reflexiva, sem o risco de cair no relativismo absoluto, ou no positivismo sem crítica.

O Campo é um sistema, ou subsistema social inserido dentro de uma Estrutura Social, que é construído a partir do compartilhamento de experiência e práticas, com uma série de crenças, habilidades e regras que vigem na lógica do campo. Torna-se de algum jeito fluído, pois o campo é fruto da construção de uma história coletiva, em que a interação dos participantes é que constrói tal história. O campo, então, seria o local de encontro e enfrentamento dos indivíduos, que interagem dentro da Estrutura Social e a estrutura do campo. Cada campo possui uma exigência, ou demanda específica de capital que reflete a disputa interna entre os agentes dentro do campo e as disputas sociais entre os 
143 | InterAção

campos. Os capitais se constituem entre o: econômico; social; cultural e o simbólico ${ }^{13}$ ( BOURDIEU,1990).

Dentro da Estrutura Social há diversos campos, como o artístico e das artes, o campo intelectual e acadêmico, campo jornalístico e midiático, campo financeiro entre outros. Cada campo possui uma lógica de funcionamento, também em função dos capitais envolvidos dentro dele, que no mesmo diapasão exibe uma hierarquia relacionada às regras e práticas e aos capitais envolvidos. A hierarquia dentro do campo é uma forma de Poder Simbólico que legitima e forma consensos entre os agentes do campo (BOURDIEU, 1989).

O habitus é a disposição de percepções, pensamentos e ações, que tem a função de delimitar o poder dentro do campo, já que é função da teorização de Bourdieu sobre campo. O habitus nada mais é que a incorporação de necessidades em resposta as condições objetivas do campo, é um estimulo de ordem estrutural do mundo prático que molda a cognição dos indivíduos. O habitus se conforma como a expressão de um processo de interação dentro de um campo, que resulta em um comportamento, em práticas e regras que são repassadas ao longo da história do campo, mas de maneira naturalizada e não reflexiva : é uma matriz de percepções, de visões e de ações, que se realiza em determinadas condições sociais (BOURDIEU, 1990).

Em outras palavras, o habitus é um conceito que mostra a hierarquia e a dinâmica de construção e reprodução do poder dentro de um campo e na estrutural social como um todo (BOURDIEU, 1990),

Logo, tanto o habitus mantêm tal estrutura hierárquica, quanto mostra que dentro da estrutura social existe um grau limitado de agência - que é discutida e

13 Porém como aponta (GUZZINI, 2000), e seguindo a mesma metodologia de Bourdieu, o capital simbólico é uma categoria específica que mesmo importante, não será abordada além da demanda que surgirá dentro dos objetivos deste trabalho. 


\section{4 | InterAção}

não consensual, como visto em autores como Bigo (2011) e Pouliot e Moránd (2013) - na medida em que é a partir da interação social e a reprodução do habitus que o campo se perpetua: Os agentes são moldados e moldam a estrutura à qual fazem parte ${ }^{14}$.

Bourdieu (1985) apud Bigo (2011) diz que os mecanismos de ação individual e coletiva num campo que partilha um habitus se dão de forma consciente e inconsciente, e que a avidez e o modus operandi se relacionam com um senso prático que vige dentro da lógica, que é fruto de disputas e objetivos inerentes àquela lógica;

Porque o habitus é uma capacidade infinita para a geração de produtos - pensamentos, percepções, expressões e ações - cujos limites são definidos pelas condições historicamente e socialmente situadas de sua produção, a liberdade condicionada e condicional que ele fornece é tão distante de criação de novidades imprevisíveis como é a partir de simples reprodução mecânica dos condicionamentos originais. (BOURIDEU 1990, p.55, grifo nosso $)^{15}$.

A estrutura, dessa forma, é reproduzida, é um fenômeno social, e não natural, em que o habitus é a reificação das relações que são produzidas no campo.

Bourdieu (1990) fala no seu capítulo "Crença e o Corpo" - e reiteram Guzzini (2000) ; Pouliot e Mérand (2013) - da importância da doxa 16 como um orientador, motivador e o produto da interação mistificadora que liga campo ao seu habitus.

\footnotetext{
${ }^{14}$ Como sera mostrado mais a frente, a agência para Bourdieu é muito mais limitada do que se interpreta da teoria de Cox, já que ele usa o conceito de hegemonia, que tem dentro dele a possibilidade de articulação social contra uma hegemonia e bloco históricos estabelecidos.

15 "Because the habitus is an infinite capacity for generating products - thoughts, perceptions, expressions and actions - whose limits are set by the historically and socially situated conditions of Its production, the condltioned and conditional freedom it provides is as remote from creation of unpredictable novelty as it is from simple mechanical reproduction of the original conditioning“.

16 Um conceito que exprime a explicação da agência, ou o conteúdo do habitus. Para se entender um habitus, é importante
} 


\section{InterAção}

Se por um lado o habitus é a manifestação do resultado da interação dos agentes do campo, esquemas e imagens coletivas pensamento e ações, seus capitais e busca por poder na hierarquia do campo, a doxa é a razão de ser ${ }^{17}$ dos agentes que reproduzem e produzem as regras e crenças profundamente arraigadas nos integrantes do campo, incorporando-as como naturais, e num cálculo prático a partir delas, "jogam o jogo" demandado por aquele campo (BOURDIEU, 1990).

O poder simbólico, e a origem da análise estrutural social de Bourdieu sob a luz dos conceitos de campo, habitus e capital, são muito em função do conceito de doxa, já que no contexto de um campo o poder é reconhecimento pelos integrantes de que um indivíduo, ou uma ação, ou pensamento é valido perante outros (BOURDIEU,1989). O indivíduo que mais consegue validar seus "capitais" dentro do campo, e tem maior domínio da lógica do funcionamento e das motivações e crenças envolvidas (habitus e doxa) possui mais poder e aceitação, essa poderia ser uma definição do que Bourdieu teorizou como Poder Simbólico. Esse pode ser comparado ao papel das ideias na teoria de Cox (1981), que será abordada mais a frente.

Apenas quem faz parte dessas interações sofre ou tem agência do poder simbólico, eu isso porque é fruto da interação social. Contando com outras categorias como habitus e doxa, que ajudam a explicar a forma, motivação e o resultado das interações sociais. Depreende-se que o poder simbólico é o produto dessas interações em termos de hierarquia, e também em termos de estrutura que reifica valores, crenças e ações, que acabam por manter as hierarquias existentes.

De outra forma, as categorias e a epistemologia que se depreende de Bourdieu a partir da descrição e análise dos seus conceitos, mostram como o papel do Estado é mais complexo do que o neorealismo adota, em adição ao

${ }^{17}$ Raison d'etre. 
146 | InterAção

grande número de publicações suas acerca da relação e função do Estado na sociedade, onde ele seria uma espécie de metacampo, ou lugar onde diversos campos convergem e disputam poder (BOURDIEU, 2014). De outra forma, podese dizer que os campos são diversos, e eles de alguma forma estão presentes dentro do Estado, e esse sofre influência dos campos de forma; i) objetiva, pelas capacidades, estruturas e relações de poder que exercem, e ii) subjetivas, quando se trata do campo e das crenças e ideias geradas pelos campos e seus habitus.

Como corolário da presença do tema Estado, são as relações de poder descritas por outras teorias, em especial a que será mais a frente tratada: Teoria Crítica de Robert Cox. O tipo de consentimento descrito através da teoria do campo e assistidos pelos conceitos de habitus e doxa, ajudam em questões relacionadas a leitura da Teoria Crítica, em que conceitos do intelectual italiano Antonio Gramsci como Hegemonia são utilizados.

Antes de empreender a comparação é importante mostrar do que se trata a teoria de Robert Cox.

\section{TEORIA CRÍTICA E ESTRUTURA HISTÓRICA DE ROBERT COX}

\subsection{ESTRUTURA HISTÓRICA}

O texto célebre Cox (1981), teve como ponto central fazer uma crítica às Relações Internacionais e às teorias que vigiam à época, da mesma forma como o construtivismo nas RI procedeu no final da mesma década (LAPID, 1989), e toda a carga contestatória do positivismo realista. 


\section{7 | InterAção}

Essa crítica se dá em diálogo com as ideias do construtivismo nas RI, aqui já abordado, em especial pelo uso das ideias de Bourdieu nas RI, em que as relações sociais importam, e elas convivem e interagem com elementos materiais da vida em sociedade, assim como elementos subjetivos, relacionados a ideias e ideologias.

Cox (1981) também traz um caráter reflexivo na sua análise, uma vez que trata a sociedade como fruto de uma Estrutura Histórica, em que para se entender a realidade é necessário perceber como as ideias e quem reproduz as ideias percebe o mundo: no caso dos intelectuais as “Teorias são feitas para alguém, e com algum objetivo. Todas as teorias tem uma perspectiva. Perspectivas derivam de uma posição no tempo e espaço, especialmente no tempo e espaço político e social"18 (COX, 1981, p.4).

Cox (1981) explora a ideia de uma sociedade estruturada em elementos que interagem entre si, a partir de condições objetivas e subjetivas, e como produto destas interações, os indivíduos formam imagens e agem no mundo.

Para exemplificar essa relação de interação, tem-se como resultado a construção de um tipo "triangulo" para ilustrar o que foi cunhado como Estrutura Histórica;

18 "Theory is always for someone for some purpose. All theories have a perspective. Perspectives derive from a position in time and space, specifically social and political time and space." 
148 | InterAção

Figura 1. Estrutura Histórica

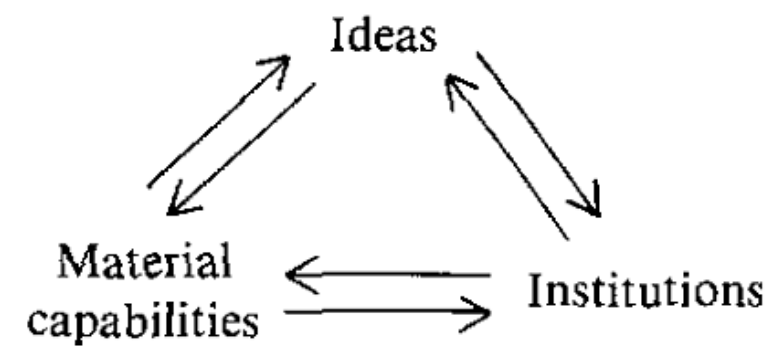

Fonte: COX (1981, p.12).

Com a Figura 1. Mostra um esquema teórico que vê ideias, capacidades materiais e instituições como forças que inter-relacionadas dentro do contexto histórico ao qual Robert Cox ser propôs analisar.

As capacidades materiais dizem respeito ao acúmulo de riquezas e tecnologias que podem ser organizadas, e promover acumulação ou destruição de riqueza. Já as ideias seriam de dois tipos: a primeira relacionada a significados intersubjetivos, ou noções compartilhadas acerca da natureza das relações, que tendem a perpetuar hábitos e expectativas de comportamento, a segunda se relaciona com "imagens coletivas de uma ordem social, sustentadas por diferentes grupos de pessoas" (COX 1981, p.12). Sem sua as imagens coletivas são : as justificativas das estruturas de poder vigentes, justiça e bens públicos ${ }^{19}$.

Cox (1981) diz que as instituições são uma forma de reproduzir uma ordem específica, ou um ponto de encontro e influência de ideias e capacidades materiais que vigem na sociedade. Entretanto elas podem ser um campo de batalha para diferentes ideias (grupos com diferentes imagens coletivas), e de

\footnotetext{
${ }^{19}$ A partir das imagens coletivas, ou do confronto delas, há uma possibilidade de mudanças nas relações sociais e na realidade social, por exemplo, a imagens coletiva que a esquerda tem de bens públicos, versus a imagem coletiva que grupos de direita possuem. Ambos os grupos veem a questão de forma diferente, e vão disputar em diversos lócus da sociedade, principalmente no Estado, para fazer valer suas ideias e visões de mundo.
} 


\section{InterAção}

alguma forma mudar tanto capacidades materiais (sua forma de acumulação ou destruição de riqueza), quanto as ideias ( a construção de imagens e percepções).

Outro fator importante sobre a Estrutura Histórica é seu limite intrínseco. Ela só pode ser entendida dentro de limites específico das diferentes realidades históricas, ou dentro dos limites de cada contexto onde a análise é feita;

Estruturas Históricas são modelos de contraste: como tipos ideais elas fornecem, de uma forma coerentemente lógicas, uma representação simplificada da realidade complexa e expressa tendências, limitadas em sua aplicabilidade no tempo e espaço, ao invés de totalmente completas e desenvolvidas. (COX 1981, p.13) ${ }^{20}$.

O autor também mostra que há uma hierarquia dentro da Estrutura Histórica, e faz isso indo a conceitos que Antonio Gramsci cunhou, e são tratados por outros autores. Por exemplo, Gill (1993) explica a “Escola Italiana” e o uso de Gramsci para uma ontologia e epistemologia de Estudo: as categorias mais importante para perceber as relações de poder e a possibilidade, ou não, de mudança são Hegemonia e Bloco Histórico.

\subsubsection{Hegemonla}

O conceito de Hegemonia faz parte do escopo teórico de Cox, e de uma linha de pensamento dentro da teoria crítica chamada Teoria Crítica Neogramsciana21. Não é possível afirmar que a obra de Cox seja uma continuação, ou uma perspectiva fiel às intenções e objetivos que Antonio

\footnotetext{
20 "Historical structures are contrast models: like ideal types they provide, in a logically coherent form, a simplified representation of a complex reality and an expression of tendencies, limited in their applicability to time and space, rather than fully realised developments".

21 Ver Gill (1993).
} 
150 | InterAção

Gramsci desenvolveu intelectualmente, mas é possível recorrer às sua ideias que delineiam um método baseado em categorias gramscianas.

Entende-se aqui que a utilização do conceito de Hegemonia feita por Cox pode ser um elo entre o que escreveu Bourdieu e as suas Estruturas de Poder, Poder Simbólico, com a Estrutura Histórica proposta por Cox: no limite é uma ligação entre as perspectivas e que interessa as RI no campo do estudo da política internacional.

Em Cox (1993) a hegemonia pode ser entendida como a construção social de um consenso relativo de um grupo que lidera e tem poder em diversos segmentos da sociedade. O grupo hegemônico não é automaticamente unânime, mas pode deter uma estrutura política, econômica e ideológica forte o suficiente para se estabelecer no poder por diversos anos ou décadas. No mesmo sentido vem a ideia de Bloco Histórico. Ele se refere à permanência de um arranjo estrutural de grupos sociais que perdura como hegemônico, no limite de outro arranjo se estabelecer e mudar o bloco histórico.

Dentro da perspectiva de Cox (1981), a hegemonia tem papel fundamental, uma vez que grupos políticos - econômicos hegemônicos formam uma hegemonia que altera a correlação de forças sociais, parte de uma interação entre capacidades materiais, instituições e ideias que expressam as relações de poder dentro da sociedade, e com potencial para extravasarem para o âmbito internacional. 
151 InterAção

\subsection{ORDEM MUNDIAL E O ESTUDO DO “INTERNACIONAL”}

Cox (1981), usa outra figura como tipo ideal para explicar a sociedade, a Estrutura Histórica, poderia ser aplicada para a relação entre as sociedades, Estado e como as relações de poder num âmbito mais amplo seriam explicadas da seguinte formas;

\section{Figura 2. Estrutura Histórica}

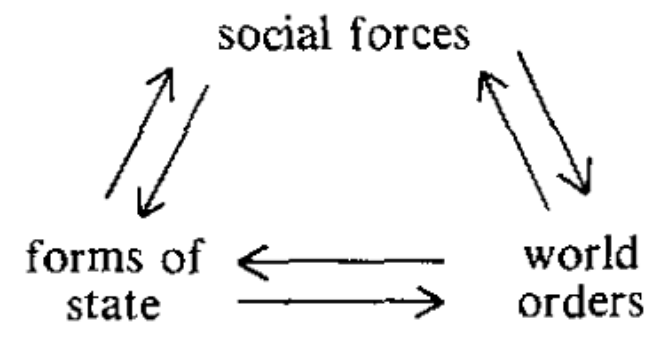

Figure 2

Fonte: COX (1981, p.14).

O autor trata cada um dos vértices como níveis, e cada nível possui um arranjo diferente dos elementos integrantes da Estrutura Histórica e são eles: Forças Sociais, Formas de Estado e Ordens mundiais ${ }^{22}$.

Como exemplo é possível falar de forças sociais ${ }^{23}$. Um sindicato é uma força social, que possui uma condição em relação as capacidades materiais

\footnotetext{
22 Ler em sentido anti-horário à partir do vértice superior.

${ }^{23} 0$ exemplo é meramente ilustrativo. Modernamente é possível falar das forças sociais ligadas ao sistema financeiro, que interagem nos contextos domésticos, ou sob uma Estrutura Histórica específica, e muda o arranjo dessa estrutura de forma considerável, ideias, capacidades materiais e instituições. Dada a penetrabilidade do capital financeiros nos países, é possível imaginar quão mais impactante seria essa Força Social ,em comparação com outras, para mudar as Formas de Estado, e estabelecer mudanças na Ordem Mundial. 0 mesmo exercício poderia ser feito, por exemplo, usando a Estrutura Histórica, para falar de mudanças nas Formas de Estado, apenas pelo fato das forças financeiras alterarem as condições domésticas de vários países e em seus governos, e promoverem mudanças que "comecem" pela perspectiva das Formas de Estado.
} 


\section{InterAção}

(trabalhador), um conjunto de ideias e imagens coletivas (demandam do Estado políticas compensatórias e redistribuição de renda), e fomentam e disputam espaços em certas instituições. A força social do nosso exemplo pode interferir na forma como o Estado nacional se organiza, sendo por exemplo um Estado que se localiza à esquerda, ele interagiria com outros Estados, e esses disputariam política-materialmente as condições que estabelecem uma Ordem Mundial. É necessário frisar que os elementos que constituem a Estrutura Histórica estão presente nos três níveis, e portanto as condições para mudança ou a agência, podem se dar de diferentes formas, não apenas pelas forças sociais, mas de arranjos e interações que mudam as Formas de Estado, ou até por algum motivo mais drástico, uma mudanças de Ordem Mundial que altere os outros níveis ${ }^{24}$.

A partir da Figura 2.é possível perceber que a agência é relevante na perspectiva de importância. Na medida em que se percebe uma mudança nas formas sociais que ocorriam à sua época, teoricamente se veria movimento de contra-hegemonia que poderia ajudar a deter, ou pelo menos mitigar, uma forma agressiva de organização social que poderia surgir, alterando também as formas de Estado, e talvez a Ordem Mundial.

\section{UM DIÁLOGO POSSÍVEL}

Os autores discutidos possuem orientações ontológicas similares, assim como uma epistemologia crítica.

\footnotetext{
${ }^{24} 0$ exemplo é meramente ilustrativo, mas pretender entrar no objetivo do autor no que respeita a forma como ele aborda a possibilidade agência num cenário, ou ambiente internacional, e como também existem limites para que haja tal agência. Não é apenas o princípio ordenador que incita reações de mudanças na configuração do ambiente internacional, mas Cox (1981) traz outros elementos, e uma gama mais complexa de fatores que incitam mudanças.
} 


\section{3 | InterAção}

De uma perspectiva dos paradigmas (KUHN, 2000), as teorias de Pierre Bourdieu e Robert Cox são diferentes, tem um corpo de formulação teórica, metodológica e de perspectiva distintas, apesar das convergências epistemológicas e ontológicas. A comparação de categorias não é peremptória para definir similitudes ou diferenças, mas pode ser um caminho que culmine em programas de pesquisa nas convergências.

Indo ao ponto, a divergência maior se encontraria nas possibilidades do poder de agência, que ambos aceitam existir. Em outras palavras, há distanciamento em se tratando de possibilidades para mudança através da agência. Em Bourdieu (1989) e Bourdieu (1990), ao tratar do poder simbólico, há indícios de divergência teórica com Cox (1981) no que se diz respeito a capacidade do indivíduo do ser consciente do seu papel na sociedade.

Em Bourdieu (1989), têm-se a impressão de que ao teorizar sobre o habitus, o autor coloca limites à capacidade do indivíduo de agir, coisa que na abordagem de Cox (1981) se percebe diferente.

Cox (1981) diz que interação social é o meio capaz de fomentar mudanças a partir de críticas formuladas por intelectuais contra uma estrutura vigente. De outra forma, pelas teoria do campo de Bourdieu isso seria dificultado, pois estando num contexto social do campo a condição de perceber reflexivamente e se questionar é reduz, e o agente acaba por reproduzir uma lógica derivada dessa interação, reificando práticas socialmente construídas como verdades naturalizadas (doxa) assim como uma visão de mundo que transforma suas motivações pessoais em resultado dessa interação. Ao que parece, desse ponto vista Bourdieu possui uma visão mais estática da sociedade, que se articula em cima de uma hierarquia rígida, com bases objetivas e bem delineadas (POULIOT e MÉRAND, 2013). 


\section{InterAção}

Todavia, mesmo na rigidez há uma série de símbolos, de relações intersubjetivas e socialmente construídas, o que denota também uma fluidez, de certa forma e acena para possibilidades agência, mesmo que sejam mais complexas, uma vez que o ciclo da estrutura que reproduz sua própria lógica estruturante seja difícil, mas nesse sentido aponta para uma possível agenda de pesquisas convergentes.

Para Leander (2011) é possível tratar Bourdieu, ao longo da sua obra, de formas diferenciadas ao que ele via como " Estruturalismo construtivista", já que ao longo dela os limites ou possibilidades de agência não são claros. Logo, mesmo com uma perspectiva rígida de Bourdieu, não há incompatibilidade entre os autores, pelo contrário aí se vê um canal de diálogo.

Em Cox (1981) a mudança acaba sendo um elemento relevante, e que fica mais claro no texto de Cox (1993), em que se explica mais atentamente este aspecto : o papel da tomada de consciência é inerente à vivência social, uma contingência das relações intersubjetivas. Tal coisa se exemplificada no conceito de intelectual orgânico, sendo esse o responsável por problematizar, compreender e divulgar certas ideias que sejam críticas a uma estrutura de dominação hegemônica de um bloco histórico. Ao expandir para as RI, Cox coloca na Estrutura Histórica uma "maleabilidade" para que politicamente ela mude, e na figura das forças sociais que avançam através dos Estados, sendo uma maneira de alterar a Estrutura Histórica, a hegemonia que vige, e em Instituições, onde o pape intelectual é bastante importante. Em suma a partir da agência e da tomada de consciência se constroem formas de provocar mudanças sociais, chegando ao ponto de alterar as formas de Estados, Forças sociais e a Ordem Mundial.

Em convergência, podemos dizer que as ideias de Pierre Bourdieu tem a possibilidade de, através da categoria campo, tanto analisar a sociedade 
155 | InterAção

capitalista pela ótica dos capitais envolvidos (econômico, cultural, social e simbólico), e as formas de dominação inerentes à essa sociedade, como campos específicos, mas de grande importância, como o político, religioso, financeiro, intelectual e etc. Em suma, as ideias de Bourdieu são férteis o suficiente para transitar no nível macro e no micro.

Também são as ideias de Cox, porém ao estabelecer a Estrutura História e a política internacional, engessa a possibilidade de análise de diferentes tipos de arranjos sociais, colocando as categorias "ideias", "instituições" e "capacidades materiais" muito abstrata e simplificadamente, não especificando de que forma certos tipos de ideias, e instituições poderiam se relacionar no capitalismo para formarem um bloco histórico, o que no limite seria insuficiente para explicar o objetivo principal de Cox : identificar as condições para promover a mudança. Ao se buscar, possivelmente, agregar teoria de campo com as categorias Habitus e doxa, enriquecer-se-ia a percepção do funcionamento de determinados arranjos sociais, que poderiam ser tratados como campos, em suas ações percepções, e principalmente utilizando a doxa, para problematizar a intenções e liturgias reificadas.

A possibilidade maior de complementaridade se encontra em um diálogo entre os elementos das respectivas estruturas sociais analisadas. Se por um lado Robert Cox parece simplificar, ou deixar muito amplamente exemplificada sua Estrutura Histórica , Pierre Bourdieu incorpora “divisões" em seus tipos ideais, como o habitus e a doxa, que parecem dar sentido e possibilidade de pesquisa empíricas mais precisar para explicar certos comportamentos e fenômenos sociais. Da mesma forma a teoria do campo de Bourdieu pode ser explorada ao abordar o tema Estado(BOURDIEU , 2014); (BIGO, 2011), e sua complexidade, onde os campos podem ajudar a suprir uma falta de especificação de Cox. 


\section{6 | InterAção}

Ainda relacionado aos Estados, Cox (1993) e Gill (1993), se propõe a tratar as RI num plano de vista estrutural com vistas no plano internacional, relacionando a teoria neogramsciana às RI. O passo que vai da conformação do Estado, que se identificou nos escritos de Bourdieu em Bigo (2011), para o estudo das RI é a possibilidade de olhar a categoria "campo" para além das fronteiras da sociedade nacional. Um mundo em que, usando as categorias de Cox, há forças sociais transnacionais, a categoria campo pode ajudar a aumentar o escopo proposto por Cox, e incorporar diferentes elementos para dentro das formas sociais, e suas relações entre Formas de Estado e Ordem Mundial de maneira mais minuciosa.

\section{CONSIDERAÇÕES FINAIS}

A partir da hipótese inicial: Há possibilidade de diálogo entre a Teoria Crítica de Robert Cox e Teoria do Campo de Pierre Bourdieu incorporada no construtivismo das Relações Internacionais, pois ambos teorizam sob um ponto de vista estrutural da sociedade e também dinâmico.

É possível traçar paralelos entre ambos os autores, assim como convergir na essência de seus argumentos relacionados a estrutura hierárquica social, as relações de poder e as explicações dos porquês de haver estruturas que se perpetuam ao longo do tempo. Os autores, percebeu-se, são complementares, na medida em que comparações diretas violariam as intenções e as peculiaridades de cada abordagem, porém ao partilharem de uma epistemologia reflexiva da sociedade e dos seus agentes, é possível traçar pontos de convergência e futuras contribuições que cada linha teórica poderia oferecer para as relações internacionais: i) A análise de fatores internos que alteram a percepção dos agentes na formulação de políticas, sendo a origem dessa percepção 
157 | InterAção

dialeticamente relacionada com fatores externos ( forças sociais, instituições e seu habitus e lideranças intelectuais), evidenciando a dinâmica desse processo e seus efeitos; ii) O Estudo da Ordem mundial, em referência a Robert Cox, porém podendo aumentar o escopo de alcance para além das forças sociais, fazendo com a existência, surgimento e efeitos tenham mais elementos explicativos ( campos e habitus), e iii) empreender mais estudos, partindo das premissas e das hipóteses advindas do diálogo entre Estrutura Histórica de Cox e a Teoria do Campo de Bourdieu, de ordem empírica, coisa que as diversas categorias de Bourdieu auxiliariam na especificação e determinação dos problemas e dos parâmetros a serem analisados.

\section{REFERÊNCIAS}

ADLER-NISSEN, Rebecca Introduction. In: ADLER-NISSEN, Rebecca. Bourdieu in International Relations: Rethinking key concepts in IR. New York: Routledge, 2013. p. 1-24.

ADLER-NISSEN, Rebecca. Bourdieu in International Relations: Rethinking key concepts in IR. New York: Routledge, 2013.

BIGO, D. Pierre Bourdieu and International Relations: Power of Practice and Practice of Power. International Political Sociology.v.5, n.3, p.225-258. 2011.

BOURDIEU, Pierre. O Poder Simbólico. Rio de Janeiro: Bertrand Brasil, 1989. 311p.

BOURDIEU, Pierre. Sobre o Estado: Cursos no Collège de France (1989-92). São Paulo: Compania das Letras, 2014. 574 p.

BOURDIEU, Pierre. The Logic of Practice. Stanford: Polity Press, 1990.

COX, Robert W. GRAMSCI, HEGEMONY AND INTERNATIONAL RELATIONS: AN ESSAY IN METHOD In: GILL, Stephen. Gramsci, Historical Materialism and international Relations. Toronto: Cambridge University Press, 1993. Cap. 1. p. 49-66. 
158 | InterAção

COX, Robert W.. Social Forces, States and World Orders: Beyond International Relations Theory. Millennium: Journal of International Studies. London, out. 1981. p. 126-155.

GIDDENS, Anthony. The Constitution of Society: Outline of the Theory of Structuration. Cambridge: Polity Press, 1984. 402 p.

GILL, Stephen. Epistemology, ontology, and the 'Italian School. In: GILL, Stephen. Gramsci, Historical Materialism and international

Relations. Toronto: Cambridge University Press, 1993. Cap. 1. p. 21-48.

GUZZINI, Stefano. A RECONSTRUCTION OF CONSTRUCTIVISM IN INTERNATIONAL RELATIONS. European Journal Of International Relations. London, fev. 2000. p. 147-182.

HOPF, Ted. The Promise of Constructivism in International Relations Theory. International Security. Vol. 23, No. 1, (Summer 1998), pp: 171-200.

KAHNEMAN, Daniel. Rápido e Devagar: Duas formas de pensar. Rio de Janeiro: Objetiva, 2012. 588 p.

KAPLAN, Morton A. The New Great Debate: Traditionalism vs. Science in International Relations. World Politics, v. 19, n. 1, Oct. 1966, pp: 1-20.

KUHN, Thomas S.. A Estrutura das Revoluções Científicas. São Paulo: Editoria Perspectiva, 1962. 258 p.

LAKATOS, Imre. Metodología de los Programas de Investigación Científica, Alianza, Madrid, 1993.

LEANDER, A. The Promises, Problems, and Potentials of a Bourdieu-Inspired staging of International Relations.International Political Sociology, v. 5, n.3, p.294-313, 2011.

NEUFELD, Mark. Reflexivity and International Relations. Millennium: Journal of International Studies, London, v. 22, n. 1, p.53-76, summer 1993.

POULIOT, Vincent e MÉRAND, Political sociology in international relations. In: ADLER-NISSEN, Rebecca. Bourdieu in International Relations: Rethinking key concepts in IR. New York: Routledge, 2013. p.43-64

WALTZ, Kenneth N. Theory of International Politics. New York: McGrawHill, 1979. 
159 | InterAção

WENDT, Alexander E.. The Agent-Structure Problem in International Relations Theory. Internacional Organization,Cambridge, v. 41, n. 3, p.335-370, jun. 1987. Quaterly.

WENDT, Alexander E. Anarchy is what states make of it: the social construction of power politics. International Organization, v. 46, n. 2, Spring 1992, pp: 391425. 